\title{
Prevalence of Self Induced Abortion by Self-Administration of Abortive Pills among Abortion-related Admissions in a Tertiary Care Centre
}

\author{
Bibechan Thapa, ${ }^{1}$ Nisha Sharma, ${ }^{\text {Y Yam Prasad Dwa' }}$ \\ 'Department of Gynaecology and Obstetrics, KIST Medical College and Teaching Hospital, Mahalaxmi-1, Lalitpur, \\ Nepal.
}

\begin{abstract}
Introduction: Each year, unsafe medical abortion costs the lives of thousands worldwide. Despite the legalization of abortion in Nepal in 2002, many still seek services from unauthorized sources. This has led to grave consequences including death. Our objective is to find out the prevalence of selfinduced abortion by self-administration of abortive pills and related complications.
\end{abstract}

Methods: It is a descriptive cross-sectional study carried out among abortion-related admissions in a tertiary care centre from June 15, 2018 to March 15, 2020. Ethical approval was taken from the institutional review committee (076/077/51). Data was collected using pre-designed profoma and analysed in Statistical Package for the Social Sciences version 26. Point estimate at 95\% Confidence Interval (CI) was calculated along with frequency and proportion for binary data.

Results: Out of 223 cases enrolled, 37 (16.6\%) (9.6-23.6 at 95\% Confidence Interval) were self-induced abortion cases by self-administration of abortion pills. The mean gestational age at time of intake of pills was $7^{+6} \pm 3^{+1}$ week of gestation. The majority were diagnosed with incomplete abortion $14(37.8 \%)$ followed by septic abortion 8 (21.6\%). A surgical evacuation was performed in 25 (67.6\%). Anaemia was observed in 19 (51.3\%) with severe anaemia in 4 (10.8\%). Blood transfusion was carried out in 14 $(37.8 \%)$. Post abortive contraception was accepted by only $16(42.3 \%)$.

Conclusions: Medical abortion is safe if done under supervision but self-induced abortion by selfadministration of abortion pills has high complications rate. Therefore, further studies exploring different dimension of the serious issue is need of time.

Keywords: abortion (induced); complications; self-administration.

\section{INTRODUCTION}

As of 2010-2014, an estimated 55.9 million abortions occur each year globally. ${ }^{1}$ At least $8 \%$ of maternal deaths occur worldwide from unsafe abortion with around 22,800 women dying yearly from its complications. Almost all abortion-related deaths occur in developing countries, with the highest being in Africa. ${ }^{2}$ In Nepal abortion was legalized in 2002, and comprehensive services were made available in $2004 .^{3}$ Still many women today are receiving unsafe services from unauthorized providers.
Medical abortion with mifepristone and misoprostol is safe for termination of pregnancy up to 63 days if practiced under medical supervision. ${ }^{4}$ Despite clear guidelines, due to easy and illegal accessibility, many women self-administer these drugs. Some consider it as a method of birth spacing and depend on it without knowing its complications ranging from severe haemorrhage to death. ${ }^{5}$

Correspondence: Dr. Bibechan Thapa, KIST Medical College and Teaching Hospital, Mahalaxmi-1, Lalitpur, Nepal. Email: bibechanthapa@gmail.com, Phone:+977-9841606316. 
Thapa et al. Prevalence of Self Induced Abortion by Self-Administration of Abortive Pills among Abortion-related Admissions...

Therefore, this study aims to find the prevalence of self-induced abortion following self-administration of abortive pills in a tertiary care center.

\section{METHODS}

This study is a descriptive cross-sectional study was done in patients diagnosed with abortion from June 152018 to March 152020 at KIST Medical College \& Teaching Hospital. Ethical approval was taken from the institutional review committee (076/077/51). All case records of in-patients mentioning women admitted with complications following self-administration of abortion pills were included while cases with complications following medical abortion done in government-accredited authorized center and service provider were excluded from the study. Data was retrieved by reviewing patients' records from the medical records department and was entered into a self-designed proforma.

Convenience sampling was done and the sample size (n) was calculated as,

$\mathrm{n}=\mathrm{Z}^{2} \times \mathrm{p} \times(1-\mathrm{p}) / \mathrm{e}^{2}$

$=(1.96)^{2} \times 0.5 \times 0.5 /(0.07)^{2}$

$=196$

Where,

$\mathrm{n}=$ required sample size

$\mathrm{Z}=1.96$ at $95 \%$ Confidence Interval $(\mathrm{Cl})$

$\mathrm{p}=$ prevalence, $50 \%$

$\mathrm{e}=$ margin of error, $7 \%$

The data was entered and analysis was carried out through Statistical Package for the Social Sciences (SPSS) version 26. The data was collected throughout the study period to meet the sample size for the study.

\section{RESULTS}

There were a total of 223 abortion cases admitted for abortion-related complications in the study period of 21 months. Out of them, 37 (16.6\%) were self-induced abortion cases done by self-administration of abortion pills. Most of them were married; $33(89.2 \%)$ and in the 20-25 years age group; 18 (48.7\%) (Table 1$)$.

Out of 37 patients, $25(67.6 \%)$ presented to the emergency room while $12(32.4 \%)$ presented to out patient department. Per vaginal bleeding 30 (81\%) was the most common presenting symptom followed by pain abdomen 29 (78.3\%). There was a history of the passage of fleshy mass in 17 (45.9\%) patients and per vaginal discharge in 5 (13.5\%). Seven (18.9\%) complained of dizziness, 5 (13.5\%) had a fever, 3 $(8.1 \%)$ presented with loss of consciousness while 1 $(2.7 \%)$ patient also had a history of abnormal body movement. The duration of symptoms ranged from 1 day to 30 days with a mean of $8.4 \pm 8.2$ days.

\begin{tabular}{|ll|}
\hline \multicolumn{2}{|l|}{ Table 1. Demographic profile of patients. } \\
\hline Variables & Frequency $\mathrm{n}(\%)$ \\
Age group & $3(8.1)$ \\
$<20$ yrs & $18(48.7)$ \\
$20-25$ yrs & $13(35.1)$ \\
$26-30$ yrs & $1(2.7)$ \\
$31-35$ yrs & $1(2.7)$ \\
$36-40$ yrs & $1(2.7)$ \\
$>40$ yrs & \\
*Ethnicity & $18(48.6)$ \\
Disadvantaged Janajatis (Magar, \\
Tamang, Rai, Lama, Tharu) \\
$\begin{array}{l}\text { Disadvantaged non-Dalit Terai } \\
\text { caste group (Yadav, Sohar, }\end{array}$ & $4(10.8)$ \\
Takur) & \\
Religious Minorities (Muslim) & $1(2.7)$ \\
$\begin{array}{l}\text { Relatively advantaged Janajatis } \\
\text { (Newar,Gurung) }\end{array}$ & $3(8.1)$ \\
Upper caste group & $11(29.7)$ \\
(Brahmin, Chhetri) & \\
Marital Status & \\
Married & \\
Unmarried & \\
\hline
\end{tabular}

*Ethnics codes as defined by Health Management Information system 2013

Gestational age (GA) has been calculated from last menstrual period using Naegele's formula. It is found that abortive medication was used as early as 30 days $(4+2$ weeks of Gestation (WOG)) and as late as 114 days $(16+2$ WOG). Mean GA at the time of selfadministration of abortive medication is $48.3 \pm 22$ days $(7+6 \pm 3+1$ WOG). Mean GA at the presentation after an abortive attempt to our facility was $64.5 \pm 20.99$ days $(9+2 \pm 3$ WOG) with a patient presenting as early as at 37 days $(5+2$ WOG) GA and as late as at (17+4 WOG) GA. The total duration from abortion attempts to presentation was a minimum of 1 day and a maximum of 52 days with a mean of $12.83 \pm 13.2$ days.

Seven $(18.9 \%$ ) cases have a previous history of induced abortion. Out of them, five $(13.5 \%)$ had a history of one previous induced abortion while two (5.4\%) had a history of two induced abortions. Most abortions were attempted before 9 weeks of gestational age in 27 (79.97\%) cases (Table 2).

On examination, minimum systolic blood pressure was $80 \mathrm{mmHg}$ and the maximum was $130 \mathrm{mmHg}$ with a mean of $102 \pm 13.3 \mathrm{mmHg}$. Likewise, the minimum mean arterial pressure was $60 \mathrm{mmHg}$, the maximum was $96.7 \mathrm{mmHg}$ with a mean of $77.8 . \pm 10.7 \mathrm{mmHg}$. 
Thapa et al. Prevalence of Self Induced Abortion by Self-Administration of Abortive Pills among Abortion-related Admissions...

Pallor was present in 15 (40.5\%) patients. Hemoglobin level measured showed a minimum of $5.3 \mathrm{gm} / \mathrm{dl}$ and a maximum of $13.5 \mathrm{gm} / \mathrm{dl}$ with a mean value of $10.45 \pm 2.36 \mathrm{mg} / \mathrm{dl}$. Fourteen $(37.8 \%)$ received blood transfusion (Table 3).

\begin{tabular}{|c|c|}
\hline $\begin{array}{l}\text { Gestational age at the time of } \\
\text { abortion attempt }\end{array}$ & Frequency n (\%) \\
\hline$<9$ weeks & $27(72.97)$ \\
\hline 9-12 weeks & $8(21.62)$ \\
\hline$>12$ weeks & $2(5.41)$ \\
\hline \multicolumn{2}{|l|}{ Gravidity } \\
\hline Primigravida & $14(37.8)$ \\
\hline Multigravida & $23(62.2)$ \\
\hline Gravida 2 & $6(26)$ \\
\hline Gravida 3 & $11(47.8)$ \\
\hline Gravida 4 & $4(17.4)$ \\
\hline Gravida 5 & $2(8.6)$ \\
\hline
\end{tabular}

\begin{tabular}{|ll|}
\hline \multicolumn{2}{|l|}{ Table 3. Anemia and blood transfusion profile. } \\
\hline Anemia & Frequency $\mathbf{n}(\%)$ \\
Mild (9-10.9) & $9(24.3)$ \\
Moderate (7-8.9) & $6(16.2)$ \\
Severe $<7$ & $4(10.8)$ \\
No anemia $>10.9$ & $18(48.6)$ \\
Blood Transfusion & \\
1 pint & $3(21.4)$ \\
2 pints & $6(42.9)$ \\
3 pints & $3(21.4)$ \\
4 pints & $2(14.3)$ \\
\hline
\end{tabular}

Majority of women $37.8 \%$ (14) were diagnosed with incomplete abortion followed by septic abortion which was present in $21.6 \%$ (8). Five (13.5\%) patients were diagnosed with ectopic pregnancy of which one was very rare case of ovarian molar ectopic pregnancy (Table 4).

\begin{tabular}{|ll|}
\hline Table 4. Diagnosis and complications. \\
\hline Diagnosis & Frequency $\mathbf{n ~ ( \% ) ~}$ \\
Incomplete Abortion & $14(37.8)$ \\
(1 incomplete abortion with UTI) & \\
Ectopic pregnancy & $5(13.5)$ \\
(2- Ruptured Ectopic, 1 Tubal & \\
abortion with a ruptured ovarian & \\
cyst, 1 Ovarian Molar Pregnancy, & \\
1 unruptured tubal ectopic & \\
pregnancy) & \\
Septic Abortion & $8(21.6)$ \\
Complete Abortion & $3(8.1)$ \\
(1 Complete abortion with UTI) & \\
\hline
\end{tabular}

\begin{tabular}{|ll|} 
Missed abortion & $3(8.1)$ \\
Failed MA (live pregnancy) & $2(5.4)$ \\
Inevitable abortion & $1(2.7)$ \\
Incomplete Abortion with H. Mole & $1(2.7)$ \\
\hline
\end{tabular}

The total duration of hospital stay was a minimum of 1 day and a maximum of 7 days with a mean of $2.97 \pm 1.44$ days. The minimum duration from last pregnancy was 5 months and the maximum duration was 132 months with mean $38.4 \pm 34.1$ months.

All the patients received antibiotic treatment. None of the patients needed critical care admission or inotropic support. Post abortive contraception counselling was provided to everyone but only $16(43.2 \%)$ accepted it (Table 5).

\begin{tabular}{|ll|}
\hline Table 5. Management modality. & \\
\hline Management & Frequency $\mathbf{n}(\%)$ \\
MVA (Manual Vacuum & $24(64.9)$ \\
Aspiration) & \\
Conservative & $6(16.2)$ \\
Laparotomy & $4(10.8)$ \\
MI (Medical Induction) & $2(5.3)$ \\
Suction \& Evacuation & $1(2.7)$ \\
Acceptance of Post-abortive Contraception rate: \\
$43.2 \%$ & \\
Type of Contraception Method & Frequency $\mathbf{n ~ ( \% ) ~}$ \\
Depo Provera & $8(50 \%)$ \\
Implants (Jadellae) & $7(43.8 \%)$ \\
IUCD & $1(6.2 \%)$ \\
\hline
\end{tabular}

\section{DISCUSSION}

In 21 months, 37 patients presented with various complications following self-administration of abortive pills. The minimum age of the women was 17 years and the maximum was 42 years with a mean age of $25.3 \pm 5.36$ years. The majority $(83.8 \%)$ were from 20 30 year of age and those greater than 30 years of age were approx $8 \%$. However, in a study conducted by Giri et al. ${ }^{6} 52 \%$ of women were of 20 -29-year age group and $44 \%$ were from the $30-39$ year age group.

In our study $37.8 \%$ were primigravida and $62.2 \%$ were multigravida. Out of the total, $16.2 \%$ were Gravida 2, and $45.9 \%$ were Gravida 3 or more including Gravida 5 (2). The percentage of Primigravida in our study was higher in comparison to other studies. In the study done by Giri et al. ${ }^{6} 79 \%$ of women were multigravida and $21 \%$ were primigravida, a similar finding was seen in K. Nivedita et al. ${ }^{7}$ In the study conducted by Singh $\mathrm{M}$ et al. $^{8} 10 \%$ were primigravida, $15 \%$ were gravida 2 , $75 \%$ were gravida 3 or more including $17 \%$ of the total who were more than gravida 5 . 
Gestational age (GA) was calculated from the last menstrual period (LMP) using Naegele's formula. It was found that abortive medication was used as early as 30 days and as late as 114 days. Mean GA at the time of self-administration of abortive medication is $48.3 \pm 22$ days. The majority $(70.27 \%$ ) of the women had self-administered abortive pills within approved GA of fewer than 9 weeks It was similar to other studies by Giri et al. ${ }^{6}$ and Jethani $\mathrm{M}$ et al. $^{9}$ which was $60 \%$. At 9 to 12 WOG, $18.9 \%$ of women had taken abortive medication while $5.4 \%$ had taken medication beyond 12 WOG. In the study conducted by Giri et al. ${ }^{6} 60 \%$ of women had consumed abortion pills within approved nine weeks gestation while $19 \%$ had consumed after nine weeks and $21 \%$ after twelve weeks.

The unmarried women belonged to the age group 2024 years and constituted $10.8 \%$ in our study. It was close to the study done by K. Nivedita et al. ${ }^{7}$ where $12.5 \%$ were unmarried but contrary to our study unmarried age group was $15-19$ years.

In our study, $94.6 \%$ of patients were admitted for 1-5 days. The maximum duration of hospital stay in our study was of 7 days. In a study conducted by $\mathrm{K}$. Nivedita et al, ${ }^{7}$ duration of hospital stay was 1-5 days which was $75 \%$ and 1 patient had a hospital stay of more than 10 days.

In our study, $37.8 \%$ of women were admitted with a diagnosis of incomplete abortion which was less in comparison to a study conducted by Giri et al. ${ }^{6}$ where $60 \%$ of cases were of incomplete abortion. Jethani M et al. ${ }^{9}$ reported $57.45 \%$, Goyal $\mathrm{N}$ et al. ${ }^{10}$ reported $75 \%$, and K. Nivedita et al. ${ }^{7}$ reported $70 \%$ of cases with an incomplete abortion. Septic abortion comprised of $21.6 \%$ in our study. On the contrary, a study done by K. Nivedita et al. ${ }^{7}$ reported $7.5 \%$ cases with septic abortion, Giri et al. ${ }^{6}$ showed $6.5 \%$, Jethani $\mathrm{M}$ et al. ${ }^{9}$ reported $4.3 \%$ and Goyal $\mathrm{N}$ et al. ${ }^{10}$ showed $5 \%$ patients with sepsis.

In our study, ectopic pregnancy was diagnosed in $13.5 \%$ of pregnancy which is higher when compared to other studies, which shows $6.5 \%$ in Giri et al. ${ }^{6} 1.06 \%$ in Jethani $\mathrm{M}$ et al. ${ }^{9}$ and $2 \%$ in Goyal $\mathrm{N}$ et al. ${ }^{10}$

In our study failed medical abortion was observed in $5.4 \%$. Near similar finding was observed in a study conducted by Jethani $\mathrm{M}$ et al. ${ }^{9}$ where $6.3 \%$ of women had live continued pregnancy. Other studies were done by Goyal $\mathrm{N}$ et al. ${ }^{10}$ had $3 \%$, Giri et al. ${ }^{6}$ reported $13 \%$ continued pregnancy and $\mathrm{K}$ Nivedita et al. ${ }^{7}$ reported a $22.5 \%$ failed abortion with continued live pregnancy. In our study two pregnancies, $5.4 \%$ had molar pregnancy which had been rarely reported in self-induced abortion.
Surgical evacuation (MVA and Suction \& evacuation) was performed in $67.8 \%$ of patients. Finding was nearly similar to Giri et al. ${ }^{6}$ which showed $71 \%$ and Singh $\mathrm{M}$ et al. ${ }^{8}$ which showed $73 \%$. Other management modalities included conservative management which was done in $16.2 \%$ (tab misoprostol in incomplete abortion, antibiotics in septic abortion, general measure incomplete abortion), laparotomy was performed in all patients with ectopic pregnancy i.e. $10.8 \%$.

In our study anemia was present in $51.4 \%$ of which severe anemia was present in $10.8 \%$. Near about findings were reported by Jethani $\mathrm{M}$ et al. ${ }^{9}$ with anemia in $57.45 \%$ of which $11.7 \%$ was severe anemia and $\mathrm{K}$. Nivedita et al. ${ }^{7}$ with anemia in $50 \%$ with severe anemia in $12.5 \%$. However, in the study conducted by Giri et al. ${ }^{6}$ anemia was present in $79 \%$ of patients and $37.5 \%$ of the patient had severe anemia.

Blood transfusion was received by $37.8 \%$ in our study. Giri et al. ${ }^{6}$ reported blood transfusion needed in $52 \%$, Jethani $\mathrm{M}$ et al. ${ }^{9}$ reported $20.21 \%$ patients, and $\mathrm{K}$ Nivedita et al. ${ }^{7}$ blood transfusion was needed in $15 \%$ of the patients. Most of the patients i.e 42.9\% required a two-pint blood transfusion in our study while Giri et al. 6 showed $29 \%$. In our study, $13.5 \%$ of patients required three pints or more of blood transfusion. In a study conducted by Giri et al. ${ }^{6} 22.9 \%$ required three or more pints of blood transfusion.

Post abortive contraception was accepted by $43.2 \%$ of whom 50\% received Depo Provera, 43.8\% Jadellae, and $6.2 \%$ received IUCD. In the study conducted by Singh $\mathrm{M}$ et al. $^{8}$ contraceptive counseling was done in all patients during their hospital stay, and patients accepted contraceptives in the hospital itself in the form of OC pill, IUCD, DMPA injection, CHHAYA, condoms, and tubal ligation was accepted by $16 \%$ cases.

\section{CONCLUSIONS}

Safe abortion services are every women's reproductive rights. Medical Abortion is safe if done under supervision by authorized personal in authorized institution following authorized standard protocols. But self-induced abortion done by self-administration of abortion pills has high complications rate. Severity of complications is too high to underestimate yet less has been explored and known about this issue. Developing countries like Nepal has high prevalence rate of Selfinduced abortion done by self-administration of abortion pills, this implies to multifactorial causation like lack of awareness of abortion services and abortion laws, lack of awareness on contraception and family planning, associated social stigma, easy availability of abortion pills over the counter and many more. 
Therefore, studies exploring different dimension of the serious issue is need of time.

\section{ACKNOWLEDGEMENTS}

Special acknowledgment for Prof. Dr. Heera Tuladhar,
Prof. Dr Amita Pradhan, Dr. Neeti Singh and RN Binita Khakda for their support.

Conflict of Interest: None.

\section{REFERENCES}

1. Ministry of Health and Population. Nepal Demographic and Health Survey 2011 [Internet]. Kathmandu, Nepal: Ministry of Health and Population, New ERA, and ICF International, Calverton, Maryland (US); 2011 [cited 2020 May 1]. Available from: https://dhsprogram.com/pubs/ pdf/FR257/FR257\%5B13April2012\%5D.pdf. [Full Text]

2. Unintended Pregnancy and Induced Abortion Worldwide [Internet]. New York, USA: Guttmacher Institute; 2018 [[updated] 2020 July; cited 2020 May 1]. Available from: https://www.guttmacher.org/fact-sheet/induced-abortion-worldwide. [Full Text]

3. Unsafe Abortion: Global And Regional Estimates Of Incidence Of And Mortality Due To Unsafe Abortion With A Listing Of Available Country Data [Internet]. Geneva, Switzerland: WHO. [citated 2020 May 1]. Available from: https://apps. who.int/iris/handle/10665/64087?show=full. [Full Text]

4. Kurtkoti K. FOGSI sssFOCUS Medical Abortion [Internet]. Pune, India: The Federation of Obstetric \& Gynaecological Societies of India (FOGSI); 2011 [cited 2020 May 1]. Available from: https://www.fogsi.org/wp-content/uploads/ fgsi-focus/medical+abortion+2011.pdf [Full Text]
5. Kaur Bajwa S, Singh Bajwa S, Singh N, Singh A, Goraya S, Kaur Ghai G. Medical abortion: is it a blessing or curse for the developing nations? Sri Lanka Journal of Obstretics and Gynaecology. 2012 Jan 23;33(3):84-90. [Full Text | DOI]

6. Giri A, Srivastav V, Suwal A, Sharma B. A Study of complications following self-administration with medical abortion pills. Nepal Journal of Obstetrics and Gynaecology. 2015;10(1):2024. [ Full Text | DOI]

7. Nivedita K, Shanthini F. Is it safe to provide abortion pills over the counter? a study on outcome following self-medication with abortion pills. J Clin Diagn Res. 2015 Jan;9(1):QC01-4. [마bMed | Full Text | DOI]

8. Singh M, Singh T. Study on self-induced unsupervised medical abortion, its complications, follow up and contraceptive counselling. Journal of Advanced Medical and Dental Sciences Research. 2017;7(2):142-4. [Full Text | DOI]

9. Jethani M, Yadav K, Muchhoria S, Sharma S. Self-Medicated Abortion- Care or Crime. Journal of Medical Science and Clinical Research. 2015 Sep;3(9):7507-12. [Full Text | DOI]

10. Goyal N, Goyal S. Outcome of self-administered medical abortion pills by patients. International Journal of Reproduction, Contraception, Obstetrics and Gynecology. 2016;5(11):3740-2. [Full Text | DOI] 